\title{
O DIREITO PÓS-MODERNO E A CODIFICAÇÃO
}

\author{
Antonio Junqueira de Azevedo \\ Professor Titular de Direito Civil da Universidade de São Paulo \\ Ex-Diretor da Faculdade de Direito da Universidade de São Paulo
}

\begin{abstract}
Resumo:
Houve mudanças do paradigma jurídico no mundo do Direito, a partir do final do século passado. Reinava, nesse tempo, o paradigma da lei, para analisar e solucionar as questões jurídicas, mas, já na primeira metade do século XX, o centro de preocupação passou a ser o juiz. Hoje, novamente, estamos vivendo modificação de paradigma: os tempos pós-modernos caracterizam-se por dúvidas sobre a capacidade da razão, hipercomplexidade $e$ interação. Essa situação está levando à alteração dos métodos para codificar e à alteração dos próprios tipos de codificação.
\end{abstract}

\begin{abstract}
:
There were changes of the juridical paradigm in the world of Law, starting from the end of last century. Reigned, on that time in Civil Law, the paradigm of the statute law (positivism), to analyze and to solve the juridical subjects but, already in the first half of the XX century, the concern center became the judge. Today, again, we are living paradigm modification; the post-modern times are characterized by doubts about the capacity of the reason, hypercomplexity and interaction. That situation is taking to the alteration of the methods to codify and to the alteration of the own code types.
\end{abstract}

Unitermos: pós-modernidade; paradigma jurídico; codificação.

\section{Sumário:}

1. Introdução; 2. Mudanças de paradigma; 3. O paradigma pós-moderno; 4. Como codificar, hoje.

\section{Introdução}

Os questionamentos e as dúvidas pós-modernas sobre a capacidade da razão para obter noções definitivas, "atingir a essência das coisas" provocam visceral revolta numa ciência tão-antiga como o Direito, em que a procura de certeza 
e objetividade constitui ponto central, "questão de honra", que atravessa milênios basta pensar no que a tradição afirma ter sido a causa da Lei das XII Tábuas: a exigência da plebe romana, que sofria com a insegurança, para que fossem postas por escrito as normas em que os patrícios baseavam suas decisões. As considerações sobre o que seja, ou-não, verdadeiro são, na pós-modernidade, deixadas de lado e substituídas pelas sobre o que seja, ou-não, útil (neopragmatismo). São de Rorty (1998) as afirmações a seguir: "Nós não temos idéia, na frase 'a realidade é como é, em si mesma', sobre o que esse 'em si mesma' supõe. Nós sugerimos, (pois), o abandono da distinção 'aparência/realidade' em favor da distinção 'mais útil/menos útil' como forma de pensar. (...) Nossos críticos, (porém), não acreditam que a distinção 'mais útil/menos útil' possa tomar o lugar de velha distinção 'aparência/realidade"'. No campo do Direito, a consideração da "realidade como é" parece ao jurista pressuposto básico para a muito procurada segurança jurídica; a simples dúvida sobre a aptidão de o pensamento refletir a realidade incomoda. Paralelamente, outra característica dos tempos pós-modernos, a hipercomplexidade, que, no mundo jurídico, se revela na multiplicidade de fontes do Direito, quer materiais - porque, hoje, são vários os grupos sociais, justapostos uns aos outros, todos dentro da mesma sociedade, mas sem valores compartilhados (shared values), e cada um querendo uma norma ou lei especial para si -, quer formais - com um sem-número de leis, decretos, resoluções, códigos dentológicos, avisos, etc. etc. quebram a permanente tendência à unidade do mundo do Direito. Em terceiro lugar, finalmente, também a interação, o ir-e-vir no mesmo nível, semelhante a um mecanismo cibernético, tudo, no Direito, sendo atualmente objeto de negociação (inclusive a Constituição e as leis), vai contra a concepção hierárquica - quando não aristocrática - que o estamento jurídico tem da Justiça.

O jurista vê-se assim, hoje, confrontado com uma realidade que o desgosta; afinal - amplificando o que foi dito -, a razão, com o nome de "motivação" é exigida em todos os atos do Estado (inciso IX, do art. 93 da Constituição da República: "Todos os julgamentos dos órgãos do Poder Judiciário serão públicos e fundamentadas todas as decisões"; inciso X: "as decisões administrativas dos tribunais serão motivadas") e, agora, vêm filósofos e jusfilósofos desconstruir toda essa milenar conviç̧ão na capacidade da razão! A desconstrução (Derrida, 1997) usa a razão contra a razão e agride o jurista tradicional; por exemplo: a decisão judicial se impõe porque é emanada do Poder, ato de autoridade, portanto, - e é somente parte do jogo jurídico, uma simulação 
coletiva, entender que a sentença é obra "de prudência". Ou ainda: todos sabem que a lei obriga porque é promulgada por quem tem comando (auctoritas, non veritas, facit legem - Grotius) e é um faz-de-conta dos juristas argumentar com a lógica, como se a lei devesse ser obedecida porque é "de razão" Ah, maldita razão que tudo quer desmistificar! Maldita razão que vem destruir a si mesma! Até onde irão um Rorty, com seu neopragmatismo antiessencialista, e um Derrida, com sua desconstrução? O que será da certeza e da objetividade do Direito?

Em segundo lugar, continuando na amplificação - agora, sobre a hipercomplexidade -, qual o futuro daquelas idéias tão-elevadas e tão-úteis de que a lei é geral, não faz acepção de pessoas e apanha a todos sem distinção? O que há de ser, se cada grupo pretender uma lei para si? Esses consumidores já conseguiram um estatuto especial e aí vêm os negros, as mulheres, os gays, os sem-teto, os sem-terra! Cada grupo quer a sua lei (Minda, 1995). Quando se passa ao Poder Judiciário e se sustenta que o juiz deve atender a cada caso concreto, que sentido tem lutar por um texto abstrato, o texto da lei?

Em terceiro lugar, finalmente, o Direito sempre foi um sistema, o sistema jurídico; como em todo sistema, há - pensemos numa célula - uma unidade estruturada com diversos elementos, em organização dinâmica; cada elemento tem a sua função. Ora, na sociedade, surgido um conflito, os órgãos de input fundamentalmente os políticos, se o conflito é social (geral), e os promotores e advogados, se o conflito é coletivo ou interindividual - introduzem o conflito no sistema jurídico. Tomemos o último caso, raciocinando com a normalidade: o advogado do autor traz a lide para o sistema, que a recebe; o sistema, em seguida, pede as alegações do réu, examina o caso e, afinal, soluciona-o por meio do órgão de output, o juiz; a sentença tem eficácia externa, pacificando o conflito sem maiores problemas. Tudo bem elaborado através dos séculos. Mas, e agora, nesse mundo pós-moderno, quando as partes resolvem os conflitos por conta própria, ou quando outros Poderes "liquidam" bancos e empresas, ou quando provimentos de órgãos paralelos - Bolsa de Valores, Justiça Desportiva, Conselho de Medicina ou OAB decidem os casos à margem do Poder Judiciário? Hoje, as próprias questões sociais estão sendo decididas fora dos Parlamentos. Tornaram-se os órgãos do sistema jurídico, especialmente os de output, dispensáveis? Será o fỉm do sistema?

A pós-modernidade, debaixo dessas três características - crise da razão, hipercomplexidade, com justaposição das diversidades e interação -, 
perceptíveis também na arquitetura, na literatura, na filosofia, na economia, nas comunicações e até mesmo nas ciências exatas, atingiu em cheio o Direito.

2. Mudanças de paradigma

As difundidas idéias de Kuhn sobre as revoluções científicas, com suas alterações de paradigma, não são conhecidas no mundo jurídico; numa espécie de compensação, também o que se passa no mundo juridico parece correr ao largo das preocupações dos historiadores da ciência. No entanto, se há um campo em que tudo parece adequado ao pensamento de Kuhn é justamente o do Direito. Sendo os paradigmas "modelos de problemas e soluções para uma comunidade de operadores" parece que, por natureza, é isto que ocorre no mundo jurídico; os operadores do Direito (juízes, advogados, promotores) passam, de geração em geração, o conhecimento de casos de conflito e, assim, transmitem, uns aos outros, o modo como esses casos podem ser resolvidos. A própria lei não deixa de ser, em cada época, a expressão consolidada de um conflito e de sua solução (nesse caso, os órgãos do sistema são, principalmente, os legisladores).

Ora, sem remontarmos a épocas mais remotas, qual era o paradigma até aproximadamente a Primeira Grande Guerra? Era o paradigma da lei. Vindos dos traumas do absolutismo, os juristas de então viam, na lei, o Direito. Para dar segurança, a norma devia ser clara, precisa nas suas hipóteses de incidência (fattispecie), abstrata, universal. Como garantia de impessoalidade, o papel do juiz, por isso mesmo, era visto como passivo (o juiz era somente a boca da lei, "la bouche de la loi" - Montesquieu); a sentença, um mero silogismo, cuja premissa maior era o imperativo hipotético do texto legal ("se A é, segue-se B" - se matar, pena de prisão); a premissa menor, o fato ("A é" ou seja, fulano matou) e a conclusão, a decisão (logo, "segue-se B" - fulano deve ser preso). A função do juiz era de um autômato; bastava verificar se havia ocorrido o fato previsto na lei e, se sim, impor a consequiência. As preocupações lógico-formais sobre a lei eram, então, tão-grandes que, na vida acadêmica, a "apoteose final" das teses consistia na apresentação de impecável definição de um instituto jurídico (muitas vezes, seguida da sugestão de um projeto de $l e i$ ).

Todavia, como escreve Kuhn - e isto ocorria claramente no final dessa época -, são as anomalias ou as violações das expectativas que exercem forte atração na comunidade científica, prenunciando crise. Não é, pois, de admirar que questões 
estatisticamente insignificantes tenham merecido, como a História revela, tanta atenção: como resolver os casos de lacuna da lei? O costume obriga? Para essas indagações, os juristas de então gastaram, como se diz, rios de tinta; afinal, essas situações punham em xeque o paradigma de que estava na lei a solução para os conflitos que os juristas deveriam resolver. E lei, vale dizer, era a lei estatal, a lei positiva - não normas religiosas ou de Direito Natural.

Após a Primeira Guerra, a generosidade de alguns espíritos, preocupados com uma Justiça mais efetiva, e também a ambição política de outros, menos altruístas, desejosos de ver o Estado agindo sem peias, levaram à visão de que a lei - rígida, inflexível, alheia à diversidade da vida -, antes que útil instrumento da Justiça, era um obstáculo a ultrapassar. O paradigma termina, pois, por mudar; os juristas deixaram de examinar as questões pelo ângulo da lei e passaram a tomar, nos seus modelos de solução, como centro, a figura do juiz (encarado com um representante do Estado). Introduziram-se, assim, nos textos normativos, os conceitos jurídicos indeterminados, a serem concretizados pelo julgador no caso a decidir, e as cláusulas gerais, como a de boa-fé (falou-se até mesmo em fuga para as cláusulas gerais, ou seja, fuga da lei para o juiz). Noções vagas, como ordem pública, interesse público, função social, tornaram-se moeda corrente no mundo jurídico, servindo a torto e a direito para as autoridades de plantão. Multiplicaramse, na doutrina, os trabalhos sobre o papel do juiz, sua função, sua independência, sobre o modo como deve interpretar, etc. Diante do novo paradigma, é claro que alguns permaneceram aferrados ao paradigma antigo, tal e qual, hoje, outros tantos, por seu turno, continuam presos a este paradigma que ora estamos descrevendo e que podemos chamar de paradigma da modernidade (por oposição ao atual, da pósmodernidade).

Examinando a questão pelo ângulo universitário, até mesmo a importância das disciplinas jurídicas se alterou. Se, no tempo do que aqui apresentamos como primeiro paradigma, eram fundamentais o Direito Civil e o Direito Comercial, na época do paradigma moderno, ocuparam a cena o Direito Processual e o Direito Administrativo; seriam estes, então, as "ciências de ponta" como se diz no jargão científico.

Pois bem, atualmente, se o mundo jurídico, ao invés de se alarmar com o que se passa, procurasse entender que estamos, outra vez, simplesmente a mudar de paradigma, talvez não se revoltasse tanto e passasse, singelamente, a perguntar: e, hoje, qual é a situação? 


\section{O paradigma pós-moderno}

O tempo que estamos a viver, em primeiro lugar, não se conforma com as noções vagas que tudo fazem depender do juiz nem, por outro lado, deseja, pura e simplesmente, uma volta ao passado com a lei abstrata e geral.

Antes de mais nada, é preciso compreender que o Direito, na verdade, não é em si um sistema autônomo; integrado na sociedade, ele é um sistema de segunda ordem, algo assim como o sistema nervoso nos seres vivos (Maturana $e$ Varela). Por isso mesmo, para cumprir sua função de absorver conflitos sem perturbar o grande corpo social, ele tem, justamente, de dar solução aos conflitos, da melhor forma possível. Ora, para cumprir seu papel, não há necessidade de, sempre, tudo levar ao juiz; este pode não ser o melhor caminho. Aos poucos, os grupos sociais descobrem outras soluções. Da fuga para o juiz, cabe hoje falar em fuga do juiz - e isto, diga-se, não diminui o Poder Judiciário, eis que este fica limitado a agir nas hipóteses em que, de fato, é necessário como julgador. Para que juiz em casos nos quais as partes admitem um árbitro? Para que juiz, se é somente para notificar alguém? Para que juiz, se é caso de resolução contratual, "rescisão" em que uma das partes já declarou expressamente que não vai cumprir o contrato? Para que juiz, se é para alterar um pacto antenupcial em que o Registro fixa a eficácia? (Aliás, neste último caso, no Brasil, nem à solução do juiz chegamos). A existência pluralista de organismos que decidem com base em seus próprios códigos deontológicos (por exemplo, conselhos de ética de advogados, médicos, publicitários) ou a de entidades como a Justiça Desportiva e a Bolsa de Valores ou, ainda, a de instituições que possuem suas próprias normas e órgãos decisórios (por exemplo, as universidades), ao invés de assustar o jurista ("Agora, nada depende da lei e do juiz"!), deve levá-lo a reconhecer a especificidade de cada situação. A lei e o juiz ficarão para os casos extremos. O paradigma jurídico, portanto, que passara da lei ao juiz, está mudando, agora, do juiz ao caso. A centralidade do caso é este: o eixo em torno do qual gira o paradigma jurídico pós-moderno.

Do ponto de vista teórico, não precisa também o professor, apavorado, afirmar, mais para si mesmo que para os discípulos, que a unidade do sistema não está perdida, porque há a Constituição e esta, cúpula do edifício, "fecha o sistema"! A frase é ilusória porque, na verdade - admitamos a desconstrução, - a Constituição é composta de muitos princípios e estes precisam ser desenvolvidos, "desenrolados" por interpretação. A Constituição não constitui por si essa tábua de salvação de uma 
pretensa reductio ad unum; ela, como todos os textos, exige leitura e permite muitos entendimentos e aplicações.

Por outro lado, pode-se afirmar que as noções vagas estão ultrapassadas e, nisto, pode-se até mesmo vislumbrar uma certa volta a aspectos do paradigma da pré-modernidade; há, hoje, outra vez, muita preocupação com a segurança jurídica. Aliás, é o próprio Direito Civil que voltou a ser a disciplina jurídica de ponta. Os publicistas ainda insistem no Direito que passou (paradigma moderno), mas hoje, glosando Lenin, pode-se dizer que "não há mais Direito Público, é tudo Direito Privado" (paradigma pós-moderno). É o Direito Civil que, atualmente, por ter como objeto a vida e, em especial, a vida e a dignidade da pessoa humana, dá sentido e conteúdo ao sistema. As noções vagas de ordem pública, interesse público e função social - muletas para o juiz e as autoridades, no paradigma anterior - já não-satisfazem. Continuam a ser, não resta dúvida, muito numerosas as leis ditas de ordem pública, especialmente as relativas à ordem pública de proteção, por oposição às da ordem pública de direção; todavia, uma lei cogente dispensa o apelo a algo além dela. A noção vaga, isto é, a ordem pública tomada exclusivamente como princípio, para fundamentar a nulidade de determinado ato ou para justificar a validade de outro, esta é que perdeu grande parte de seu campo de aplicação; a ordem pública como idéia abstrata somente tem cabimento, nos novos tempos, em duas únicas hipóteses, isto é, como proteção à vida, em geral, e à vida $e$ à dignidade da pessoa humana, em particular; fora disso, o princípio de ordem pública não tem mais aplicação. Ocorre algo parecido com a noção de interesse público; para verificação de quanto o novo paradigma repele as noções vagas, basta lembrar as alegações de ex-ministros do Estado, feitas pela imprensa, há poucos meses, de que providências por eles tomadas a favor, ou contra, determinados concorrentes em leilão de telefonia visavam ao "interesse público"; qualquer um percebe o inconveniente da falta de conteúdo dessa expressão. Quem diz, e com quais critérios, o que é interesse público? O novo paradigma exige vetores materiais, diretrizes, e não fórmulas vazias, próprias de uma axiologia formal, cujo "recheio" é posto arbitrariamente pela autoridade (juiz ou membro do Poder Executivo). Para a expressão "função social", por sua vez, os próprios constituintes de 1988, no espírito da pós-modernidade, ainda que, como é óbvio, alheios ao que acontece na teoria, deram vetores materiais para sua caracterização (v. arts. $182, \S 2^{\circ}$ e art. 186 da Constituição). 
4 Como codificar, hoje.

O Projeto de Código Civil, ainda em curso na Câmara, é um exemplo do paradigma ultrapassado. Esta afirmação, diga-se antes de mais nada, é uma simples verificação de fato, e não, evidentemente, uma apreciação sobre seus coordenadores e colaboradores, vivos ou mortos. O Projeto, elaborado essencialmente entre 1969 e 1972, foi feito de cima para baixo, no tempo do Estado forte, e exige inutilmente a presença do juiz togado em inúmeras situações (por exemplo, para declaração de resolução de contrato, quando isto não é necessário, como na quebra antecipada do contrato; para algumas hipóteses de anulação por vício de vontade; para conversão de união estável em casamento; para alteração de pacto antenupcial; etc. Infelizmente, não é possível expor aqui o conteúdo da objeção em cada um desses casos). O Projeto serve-se também largamente de noções vagas (por exemplo, função social dos contratos) e pretende a todo custo manter a concepção de unidade do Direito Privado.

Ora, conforme tudo o que foi dito, vê-se bem que nada disso corresponde aos dias que correm. Para codificar, hoje, pelo menos duas diretrizes fundamentais devem ser seguidas. Em primeiro lugar, nada de um código; são necessários vários - é, aliás, o que, na prática, está a acontecer no mundo todo (tratase de conseqüência da hipercomplexidade e da desistência da tentativa de reduzir tudo à unidade). Para o Direito Civil, deveria haver um Código das Obrigações, precedido de Parte Geral, e mais, no mínimo, um Código de Família, um Código do Meio Ambiente e dos Direitos Reais, um Código dos Direitos da Personalidade e um Código de Direito das Sucessões, além, naturalmente, de leis especiais (locação, criança e adolescente, minas, etc). Somente esse fracionamento permitiria - e esta é a segunda diretriz fundamental - a participação popular efetiva, na elaboração da lei (tem de haver a interação). De novo, o Projeto de Código Civil representa aqui um exemplo negativo: quem o leu por inteiro? Os próprios senadores o aprovaram por voto de liderança! (Que diferença das discussões, na primeira metade do século, sobre o Código Civil vigente!). O Projeto tornou-se um "código secreto" Para o mundo atual, cabe perguntar: é possível o acompanhamento popular de um Código de mais de 2 mil artigos, com temas díspares, na complexa sociedade pós-moderna? A verdade é que qualquer comissão encarregada da elaboração de um dos códigos sugeridos deve, primeiramente, como fizeram os holandeses com seu Código Civil, de 1992, o mais recente da Europa, apresentar à sociedade as teses fundamentais 
(foram as "52 teses" do Código Civil holandês) e, assim, procurar conhecer a opinião dos estamentos interessados. Hoje, somente com o fracionamento dos campos temáticos e seu exame progressivo se torna possível codificar de modo interativo, participativo, democrático, pós-moderno.

Resta, para finalizar, dizer uma palavra a respeito das dúvidas contemporâneas sobre a razão. Após um primeiro susto, os muitos séculos de História do Direito devem, na verdade, levar o jurista a aplaudir as tentativas de desconstrução. A História comprova a existência de mudanças e, por outro lado, nada melhor para a realização da Justiça que a tomada de consciência do que está subjacente à lei ou à sentença. O reconhecimento da precariedade da razão, se, de um lado, leva à não-admissão de dogmas lógicos (esses dogmas, de resto - e nisto é preciso atenção -, não se confundem com os dogmas de fé e moral, que têm outros fundamentos), de outro, não impõe a conclusão de que estamos a viver a consagração do irracionalismo. Verificada a fragilidade da razão, não deve, pois, o jurista afastá-la, mas sim colocar ao seu lado, como um arrimo, a intuição do justo. Afinal, interpretar, como revelam alguns profundos trabalhos de hermenêutica (Coreth, Grondin), não é apenas "entender intelectualmente" é também intuir especialmente no caso do Direito, em que o objetivo final é manter a vida e resolver os problemas existenciais da pessoa humana no seu relacionamento recíproco. Saudemos, pois, sem medo, também esse aspecto do mundo pós-moderno.

São Paulo, agosto de 1999.

Bibliografia

CORETH, Emerich. "Questões Fundamentais de Hermenêutica" trad. de Carlos Lopes de Matos, São Paulo, Edusp, 1973.

DERRIDA, Jacques. "Du droit à la philosophie" Paris, Galilée, 1990.

DERRIDA, Jacques e CAPUTO, John. "Deconstruction in a Nutshell". Nova York, Fordhan University Press, 1997.

GRONDIN, Jean. "L'horizon herméneutique de la pensée contemporaine" Paris, Vrin, 1993.

KUHN, Thomas S. "The Structure of Scientific Revolutions", $3^{\mathrm{a}}$ ed., Chicago, The University of Chicago Press, 1996. 
MATURANA, Humberto R. e VARELA, Francisco J. "The Tree of Knowledge" Boston, New Science Library, 1988.

MINDA, Gary. "Postmodern Legal Movements" Nova York, New York University Press, 1995.

RORTY, Richard; HABERMAS, Jurgen e KOLAKOWSKI. "Debating The State of Philosophy": Westport-Connecticut, Praeger, 1996.

RORTY, Richard. "Truth and Progress" Cambridge, Cambridge University Press, 1998. 